\title{
Preparation of Fischer-Tropsch cobalt catalysts supported on carbon nanofibers and silica using homogeneous deposition-precipitation
}

\author{
G.L. Bezemer, P.B. Radstake, V. Koot, A.J. van Dillen, J.W. Geus, K.P. de Jong* \\ Department of Inorganic Chemistry and Catalysis, Debye Institute, Utrecht University, PO Box 80 083, 3508 TB Utrecht, The Netherlands
}

Received 5 August 2005; revised 14 November 2005; accepted 15 November 2005

Available online 13 December 2005

\begin{abstract}
Homogeneous deposition-precipitation on either a silica or carbon nanofiber (CNF) support of cobalt from basic solution using ammonia evaporation was studied and compared with conventional deposition from an acidic solution using urea hydrolysis. In the low-pH experiment, the interaction between precipitate and silica was too high; cobalt hydrosilicates were formed requiring a reduction temperature of $600{ }^{\circ} \mathrm{C}$, resulting in low cobalt dispersion. Lower interaction in experiments performed in a basic environment yielded a well-dispersed $\mathrm{Co}_{3} \mathrm{O}_{4}$ phase on silica, and after reduction at only $500^{\circ} \mathrm{C}$, a catalyst with $13-\mathrm{nm}$ cobalt particles was obtained. On CNF from an acidic solution, cobalt hydroxy carbonate precipitated and displayed a low interaction with the support resulting after reduction at $350^{\circ} \mathrm{C}$ in a catalyst with 25 -nm particles. From basic solution we obtained high dispersion of cobalt on the $\mathrm{CNF}$, probably related to the greater ion adsorption. After drying, $\mathrm{Co}_{3} \mathrm{O}_{4} \mathrm{crystallites}$ were obtained that, after reduction at $350{ }^{\circ} \mathrm{C}$, resulted in a catalyst with 8-nm Co particles. Samples prepared in the high-pH experiment had 2-4 times higher cobalt-specific activity in the Fischer-Tropsch reaction than their low-pH counterparts. CNF support materials combined with the high-pH deposition-precipitation technique hold considerable potential for cobalt-based Fischer-Tropsch catalysis.
\end{abstract}

(c) 2005 Elsevier Inc. All rights reserved.

Keywords: Catalyst preparation; HDP; CNF; CO hydrogenation

\section{Introduction}

Research on Fischer-Tropsch cobalt catalysts has been largely confined to cobalt on oxidic supports, generally prepared by an impregnation technique. A drawback of these support materials is their reactivity toward cobalt, which during preparation or catalysis results in the formation of mixed compounds that are reducible only at high reduction temperatures [1-4]. To avoid these problems, the use of carbon as a support has been explored [5,6]. However, the carbon materials used up to now (i.e., activated carbons) have been ill-defined and not very pure. Consequently, we decided to use well-defined carbon nanofibers (CNF) as a support. CNF is a novel support material with an attractive mesoporous and macroporous structure with high potential in many (catalytic) applications [7-11]. It consists of interwoven fibers of graphitic carbon

\footnotetext{
* Corresponding author. Fax: +31302511027.

E-mail addresses: g.l.bezemer@ chem.uu.nl (G.L. Bezemer), k.p.dejong@chem.uu.nl (K.P. de Jong).
}

with high purity, high mechanical strength, and high chemical inertness. This latter feature makes the application of a dispersed cobalt phase a challenging task. In this paper we investigate the deposition precipitation of cobalt on CNF supports.

Commonly, loading preshaped support bodies with a precursor of a catalytically active metal is done by an ion-adsorption or incipient wetness impregnation technique [12-17]. Although these techniques have great practical simplicity, general drawbacks are the low maximum loadings and the sometimes unsatisfactory distribution and low dispersion of the active phase in the ultimate catalysts $[18,19]$.

The homogeneous deposition-precipitation (HDP) technique has been developed for the preparation of highly loaded and highly dispersed oxide-supported metal catalysts (e.g., $\mathrm{Cu}$ or $\mathrm{Ni}$ on silica) [20-25]. With HDP, a solvated metal precursor is deposited exclusively onto the surface of a suspended support by the slow and homogeneous introduction of a precipitating agent, generally hydroxyl ions, in such a way as to avoid nucleation of a solid precursor compound in the bulk solution. 
Generally, the hydrolysis of urea at $90^{\circ} \mathrm{C}$ is used to achieve the required slow and homogeneous increase in $\mathrm{pH}$.

In the deposition process, the adsorption of the metal ions onto the support coincides with nucleation and growth of a surface compound. With oxidic supports, this compound consists mainly of a mixed (hydr)oxide of the metal ion and the support [20-23]. Its formation and growth prevents nucleation in the solution, and on its reduction, generally by hydrogen, the desired small, thermostable supported metal particles are generated [20, 25]. Only few papers on the preparation of carbon-supported metal catalysts with the HDP method have been published to date. Prinsloo reported on the preparation of cobalt and iron Fischer-Tropsch catalysts, but unfortunately without providing details on metal dispersion and catalytic performance [26,27]. The preparation of nickel on CNF catalysts was described by Bitter et al., who succeeded in the preparation of well-dispersed $\mathrm{Ni}$ up to at least $45 \mathrm{wt} \%$, which is remarkable because the formation of a mixed compound with the support is not possible [28]. We have extended the work of these authors with a detailed study on the deposition of $\mathrm{Co}^{2+}$ ions on CNF by HDP. In many respects, the chemistry of $\mathrm{Co}^{2+}$ resembles that of $\mathrm{Ni}^{2+}$, and thus it can be assumed that highly loaded $\mathrm{Co} / \mathrm{CNF}$ catalysts can be prepared using this HDP method.

Hydrolysis of urea at $90^{\circ} \mathrm{C}$ was used to achieve the homogeneous production of hydroxyl ions to increase the $\mathrm{pH}$ from acidic to around neutral - at this temperature, a $\mathrm{pH}$ of around 6 . Besides this traditionally used HDP procedure, we used a method developed by Lok $[29,30]$ in which the $\mathrm{pH}$ is homogeneously decreased from moderately basic to neutral values by controlled evaporation of ammonia from an ammonia/carbonate buffer solution at $90^{\circ} \mathrm{C}$. To follow the precipitation processes, the course of the $\mathrm{pH}$ was monitored as a function of time. From the difference between the $\mathrm{pH}$ curves with and without support, conclusions can be drawn concerning the nucleation and precipitation process. Additional information on the precipitation processes was obtained from the development of Co loading over time. Precipitations were performed on both activated CNF and an oxidic silica support. The precipitates were characterized after drying and after reduction by $\mathrm{H}_{2}$ chemisorption TEM, TGA-MS, TPR, XRD, and XRF, with Fischer-Tropsch catalysis experiments carried out at atmospheric pressure.

\section{Experimental}

CNF of the fishbone type with a diameter of about $30 \mathrm{~nm}$ were grown from synthesis gas and purified as described previously [31]. These "as-synthesized" CNFs were activated by refluxing in concentrated $\mathrm{HNO}_{3}$ as described by Toebes et al. [32]. After washing and drying at $120^{\circ} \mathrm{C}$, samples with a BET surface area of $180 \mathrm{~m}^{2} / \mathrm{g}$ were produced. Silica with a surface area of $196 \mathrm{~m}^{2} / \mathrm{g}$ was used as obtained from Degussa (Aerosil 200).

\subsection{Deposition-precipitation starting at low $\mathrm{pH}$}

Deposition-precipitation to prepare catalysts with intended cobalt loadings of $15 \mathrm{wt} \%$ using urea hydrolysis at $90^{\circ} \mathrm{C}$ was
Table 1

Samples prepared

\begin{tabular}{lllc}
\hline Codes & Precursor & $\begin{array}{l}\text { Co loading }^{\mathrm{a}} \\
(\mathrm{wt} \%)\end{array}$ & $\begin{array}{l}\text { Dispersion } \\
(\%)\end{array}$ \\
\hline $\mathrm{L}-$-un & $\mathrm{Co}\left(\mathrm{NO}_{3}\right)_{2} \cdot 6 \mathrm{H}_{2} \mathrm{O}$ & - & - \\
$\mathrm{H}-$ un & $\mathrm{Co}\left(\mathrm{CO}_{3}\right)_{2} \cdot 4 \mathrm{H}_{2} \mathrm{O}$ & - & - \\
$\mathrm{L}-\mathrm{CNF}$ & $\mathrm{Co}\left(\mathrm{NO}_{3}\right)_{2} \cdot 6 \mathrm{H}_{2} \mathrm{O}$ & 10.8 & 3.9 \\
$\mathrm{H}-\mathrm{CNF}$ & $\mathrm{Co}\left(\mathrm{CO}_{3}\right)_{2} \cdot 4 \mathrm{H}_{2} \mathrm{O}$ & 15.0 & 12.2 \\
$\mathrm{~L}-\mathrm{SiO}_{2}$ & $\mathrm{Co}\left(\mathrm{NO}_{3}\right)_{2} \cdot 6 \mathrm{H}_{2} \mathrm{O}$ & 15.0 & $2.5^{\mathrm{b}}$ \\
$\mathrm{H}-\mathrm{SiO}_{2}$ & $\mathrm{Co}\left(\mathrm{CO}_{3}\right)_{2} \cdot 4 \mathrm{H}_{2} \mathrm{O}$ & 15.0 & $7.3^{\mathrm{b}}$ \\
\hline
\end{tabular}

${ }^{\text {a }}$ Loading as measured by XRF and AAS.

b Highest dispersion as measured by $\mathrm{H}_{2}$ chemisorption.

performed under a nitrogen atmosphere using double-walled glass equipment as described previously [20,21]. Typically, $5 \mathrm{~g}$ of powdered support $\left(\mathrm{CNF}\right.$ or $\left.\mathrm{SiO}_{2}\right)$ was suspended in $220 \mathrm{ml}$ of demiwater to which $4.35 \mathrm{~g} \mathrm{Co}\left(\mathrm{NO}_{3}\right)_{2} \cdot 6 \mathrm{H}_{2} \mathrm{O}$ (Acros p.a.) was added. For deposition using urea decomposition, the $\mathrm{pH}$ of the suspension at room temperature was adjusted to 3.0 by adding $\mathrm{HNO}_{3}$ (Merck p.a.). Then the temperature was increased to $90^{\circ} \mathrm{C}$, after which $2.70 \mathrm{~g}$ of urea (Acros p.a.) in $30 \mathrm{ml}$ was added. The $\mathrm{pH}$ of the slurry was monitored over time. After at most $16 \mathrm{~h}$, when the $\mathrm{pH}$ reached a value close to neutral, the suspension was cooled to room temperature and filtered. The solid was washed with demiwater and dried at $120^{\circ} \mathrm{C}$ in air. Catalyst precursors were reduced in $\mathrm{He}_{2} / \mathrm{H}_{2}(3 / 1 \mathrm{v} / \mathrm{v})$ at $600^{\circ} \mathrm{C}$ $\left(\mathrm{Co} / \mathrm{SiO}_{2}\right)$ or $350^{\circ} \mathrm{C}(\mathrm{Co} / \mathrm{CNF})$ for $2 \mathrm{~h}$. To investigate the role of the support during cobalt precipitation, experiments without a support were also performed. The samples summarized in Table 1 are coded L-un (precipitated from acidic solution without support), L-CNF (precipitated from acidic solution in the presence of CNF), or $\mathrm{L}_{-} \mathrm{SiO}_{2}$ (precipitated from acidic solution with silica present).

\subsection{Deposition-precipitation starting at high $\mathrm{pH}$}

Preparations of high $\mathrm{pH}$ were done in the same doublewalled glass equipment, the only difference being that a $120-\mathrm{ml}$ polypropylene vessel was inserted in the glass vessel to suppress deposition of solid material on the walls. Typically, $0.74 \mathrm{~g}$ of $\mathrm{Co}\left(\mathrm{CO}_{3}\right) \cdot 0.1 \mathrm{H}_{2} \mathrm{O}$ (Acros) was dissolved in $27.70 \mathrm{~g}$ of $25 \mathrm{wt} \%$ ammonia (Merck pure) to which $77.30 \mathrm{~g}$ demiwater and $5.47 \mathrm{~g}\left(\mathrm{NH}_{4}\right)_{2} \mathrm{CO}_{3}$ (Acros p.a.) were added $(\mathrm{pH} \sim 11)$. After this dark-red solution was filtered, $2.0 \mathrm{~g}$ of support was suspended into it. Nitrogen was flushed through the system at a rate of $200 \mathrm{ml} / \mathrm{min}$. The system was provided with a cooler to minimize water evaporation. The temperature of the suspension was raised from room temperature to around $90^{\circ} \mathrm{C}$ and maintained there during the precipitation process. The $\mathrm{pH}$ was recorded during the entire process. After the reaction was completed (indicated by the colourlessness of the supernatant and a $\mathrm{pH}$ of about 8), the mixture was cooled to room temperature and filtered. The solid was washed three times with demiwater and dried at $120^{\circ} \mathrm{C}$ in air. Catalyst precursors were reduced in $\mathrm{He} / \mathrm{H}_{2}(3 / 1 \mathrm{v} / \mathrm{v})$ at $500{ }^{\circ} \mathrm{C}\left(\mathrm{Co} / \mathrm{SiO}_{2}\right)$ or $350^{\circ} \mathrm{C}(\mathrm{Co} / \mathrm{CNF})$ for $2 \mathrm{~h}$. To investigate the role of the support during cobalt precipitation, experiments were also performed without any support present. The samples were coded as $\mathrm{H}-\mathrm{un}, \mathrm{H}-\mathrm{CNF}$, and $\mathrm{H}-\mathrm{SiO}_{2}$, 
Table 2

Influence of reduction temperature on apparent cobalt dispersion of $\mathrm{L}_{-} \mathrm{SiO}_{2}$ and $\mathrm{H}-\mathrm{SiO}_{2}$

\begin{tabular}{lll}
\hline $\begin{array}{l}\text { Temperature } \\
\left({ }^{\circ} \mathrm{C}\right)\end{array}$ & $\begin{array}{l}\mathrm{L}-\mathrm{SiO}_{2} \\
(\%)\end{array}$ & $\begin{array}{l}\mathrm{H}-\mathrm{SiO}_{2} \\
(\%)\end{array}$ \\
\hline 400 & 0.07 & 5.7 \\
500 & 0.43 & 7.3 \\
600 & 2.50 & 5.5 \\
700 & 2.11 & 5.4 \\
900 & 2.05 & 5.0 \\
\hline
\end{tabular}

indicating the high $\mathrm{pH}$ at which the deposition process began (Table 1).

\subsection{Analysis and characterization}

During each of the preparations described above, samples of the liquid phase were collected to determine the development of the cobalt ion concentration over time. Samples were diluted to concentrations of $30-150 \mathrm{ppm}$ cobalt using $0.1 \mathrm{M} \mathrm{HNO}_{3}$. Cobalt concentrations were measured by flame atomic absorption spectroscopy (AAS) on a Varian SpectrAA-10 at $346.6 \mathrm{~nm}$.

Cobalt ion adsorption on the supports before the addition of urea was determined in separate experiments in which the solid phase was analysed. Now $1 \mathrm{~g}$ of support was slurried for $1 \mathrm{~h}$ in $50 \mathrm{ml}$ of the cobalt solutions described above. To prevent the start of deposition due to ammonia evaporation, the temperature was restricted to room temperature for the high-pH preparations. Adsorptions in acidic solutions were done both at room temperature and at $90^{\circ} \mathrm{C}$. The support was collected by filtration, followed by thorough washing. A portion of the support was resuspended in a known volume of $0.1 \mathrm{M} \mathrm{HNO}_{3}$. After filtration, the cobalt concentration in this solution was determined using AAS as described above. The cobalt loading on the CNFsupported catalysts was also determined using this method.

$\mathrm{X}$-Ray fluorescence, used to determine the cobalt loading on the silica support, was measured on a Goffin Meyvis Spectro X-lab 2000. The dried catalyst precursors and the reduced catalysts were examined with transmission electron microscopy (TEM) in a FEI Tecnai12 operated at $120 \mathrm{kV}$ or in a FEI Technai20F operated at $200 \mathrm{kV}$. Samples were crushed and suspended in ethanol under ultrasonic vibration. A drop of this suspension was brought onto a holey carbon film on a copper grid.

Powder X-ray diffraction (XRD) patterns were measured using an Enraf-Nonius CPS 120 powder diffraction apparatus with $\mathrm{Co}-\mathrm{K}_{\alpha}$ radiation $(\lambda=1.789 \AA)$. Thermogravimetric analysis (TGA) on a Netzsch STA-429 thermo balance was used to study the dried unsupported samples. The gases evolved were monitored by a Fisons Thermolab quadropole mass spectrometer through a capillary situated directly above the sample cup.

Temperature-programmed reduction (TPR) was executed with an Autochem 2920 instrument from Micromeritics using a heating rate of $5{ }^{\circ} \mathrm{C} / \mathrm{min}$ and a $5 \% \mathrm{H}_{2} / \mathrm{Ar}$ flow. Hydrogen chemisorption measurements were done with a Micromeritics ASAP 2010C. Before each measurement, a sample was dried in vacuum at $120^{\circ} \mathrm{C}$ overnight and reduced for $2 \mathrm{~h}$ in flowing $\mathrm{H}_{2}$ at $350^{\circ} \mathrm{C}(\mathrm{CNF})$ or at $400,500,600$, 700 , and $800^{\circ} \mathrm{C}\left(\mathrm{SiO}_{2}\right)$, at a heating rate of $5^{\circ} \mathrm{C} / \mathrm{min}$. After reduction, the samples were evacuated at this temperature for $30 \mathrm{~min}$. The $\mathrm{H}_{2}$-adsorption isotherms were measured at $150^{\circ} \mathrm{C}$, as recommended by Reuel and Bartholomew [33]. The $\mathrm{H} / \mathrm{Co}$ atomic ratios at zero pressure were found by extrapolating the linear part of the isotherm of the total amount of hydrogen adsorbed. Particle size estimations were based on cobalt particles with spherical geometry, assuming complete reduction and an $\mathrm{H} / \mathrm{Co}$ adsorption stoichiometry of 1 , using the formula $d=81.6 \mathrm{~W} / \mathrm{X}$, where $\mathrm{d}$ is the cobalt particle diameter $(\mathrm{nm}), W$ the weight percentage of cobalt, and $X$ is the total hydrogen uptake, in micromoles per gram of catalyst [33].

\subsection{Catalytic testing}

The Fischer-Tropsch measurements were carried out at $220^{\circ} \mathrm{C}$ and at $1 \mathrm{bar} \mathrm{CO} / \mathrm{H}_{2}(1: 2 \mathrm{v} / \mathrm{v})$. Typically, $50 \mathrm{mg}$ of catalyst particles $(0.5-1.0 \mathrm{~mm})$ was diluted with $200 \mathrm{mg}$ of $\mathrm{SiC}$ $(0.2 \mathrm{~mm})$ to achieve isothermal plug-flow conditions. Hydrocarbon products $\left(\mathrm{C}_{1}-\mathrm{C}_{16}\right)$ were analyzed with a flame ionization detector on a Varian 3800 gas chromatograph with a fused silica CP-Sil 5CB column. Selectivities of the catalysts were compared at the same CO conversion rate $(2 \%)$, achieved by adjusting the flow. Reported catalytic performances are stabilized values after 2 days of operation.

\section{Results and discussion}

\subsection{Precipitation starting from low $\mathrm{pH}$}

\subsubsection{Analysis of $\mathrm{pH}$ curves and cobalt deposition}

The first $6 \mathrm{~h}$ of the $\mathrm{pH}$-time curves monitored during the precipitation with and without support are shown in Fig. 1A. The course of the corresponding amount of deposited cobalt as measured with AAS is shown in Fig. 1B. For unsupported cobalt (L-un; Fig. 1), the onset of precipitation was observed at a $\mathrm{pH}$ of about 6.6 after $0.5 \mathrm{~h}$. At this $\mathrm{pH}$, the solution obviously had become sufficiently supersaturated to enforce nucleation and growth of a precipitate. Equilibrium was reestablished by enhanced consumption of hydroxyl ions, as indicated by a small but rapid drop of the $\mathrm{pH}$ to a value of 6.3 [20,21]. Subsequently, the $\mathrm{pH}$ was virtually constant, finally increasing to 6.4 after $18 \mathrm{~h}$. From the equilibrium $\mathrm{pH}$ of 6.3 and the starting $\mathrm{Co}^{2+}$ concentration (i.e., $60 \mathrm{mM} / \mathrm{l}$ ), a solubility product for $\mathrm{Co}(\mathrm{OH})_{2}$ can be calculated as roughly $3.0 \times 10^{-15} \mathrm{~mol}^{3} / 1$, which is close to the value of $1.6 \times 10^{-15} \mathrm{~mol}^{3} / 1$ at $20^{\circ} \mathrm{C}$ for $\beta-\mathrm{Co}(\mathrm{OH})_{2}$ reported previously [34]. The difference observed is probably because we measured at a higher temperature and in our case no $\beta-\mathrm{Co}(\mathrm{OH})_{2}$ had precipitated but Co hydroxide with intercalated anions, that is, $\alpha-\mathrm{Co}(\mathrm{OH})_{2}$. The AAS data indicate that with L-un, only a limited amount of cobalt had deposited before the maximum in $\mathrm{pH}$ had been reached, which could also reflect the experimental error in our method. At $4 \mathrm{~h}$ after the addition of urea, only $27 \%$ of the cobalt had deposited; this amount increased to a final value of $68 \%$. This incomplete deposition was 

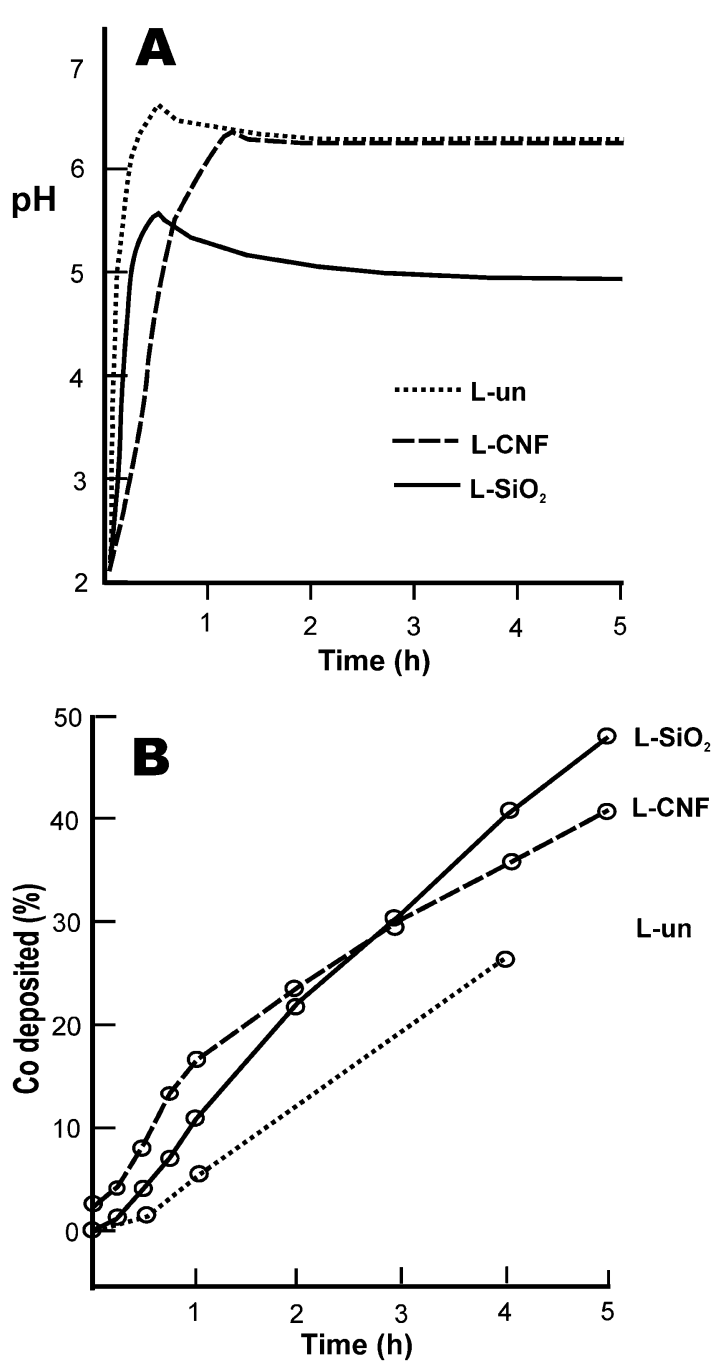

Fig. 1. $\mathrm{pH}$ curves during precipitation from low $\mathrm{pH}$ (A) with corresponding cobalt deposition as function of deposition time (B).

also indicated by the pinkish colour of the solution, and it reflects the solubility of cobalt hydroxide at the prevailing $\mathrm{pH}$. Visual inspection showed that most cobalt hydroxide was deposited on the wall of the vessel and on the $\mathrm{pH}$ electrode.

For $\mathrm{L}_{-} \mathrm{SiO}_{2}$, the onset of precipitation began at a $\mathrm{pH}$ of 5.6, also after $\sim 0.5 \mathrm{~h}$. Subsequently the $\mathrm{pH}$ decreased rapidly, then more gradually, reaching 4.9 after about $3 \mathrm{~h}$. At around $13 \mathrm{~h}$ after addition of urea, the $\mathrm{pH}$ began to increase, reaching 6.0 after $23 \mathrm{~h}$. The increase in $\mathrm{pH}$ indicates that precipitation of cobalt had come to completeness, as confirmed by the colourless filtrate. Interesting information comes from the corresponding AAS measurements (Fig. 1B). Ion adsorption for $1 \mathrm{~h}$ at the starting $\mathrm{pH}$ did not result in uptake of any cobalt with the support, independent of the temperature, and, in addition, no cobalt was found on the support during the first $15 \mathrm{~min}$ of the reaction. At $30 \mathrm{~min}$, the cobalt loading was measured as $0.6 \mathrm{wt} \% \mathrm{Co}$; this loading increased rapidly to $7.2 \mathrm{wt} \%(48 \%)$ by $5 \mathrm{~h}$. The deposition rate slowly decreased over the next $3 \mathrm{~h}$, accompanying the decrease of $\mathrm{pH}$ from 5.6 to 4.9 and reflecting the decreasing hydroxyl concentration. From the deposition rate between 4 and $5 \mathrm{~h}$, we calculated that deposition would be completed after $12 \mathrm{~h}$, which coincided nicely with the onset of $\mathrm{pH}$ increase (data not shown).

From these $\mathrm{pH}$ curves and the AAS data, it may be concluded that the presence of the silica support greatly influenced the precipitation process. Precipitation was faster on the silica support, as is clear from the greater deposition after $4 \mathrm{~h}$. The considerable shift of the $\mathrm{pH}$ to lower values demonstrated the strong interaction of the cobalt precipitate with silica, and the difference in equilibrium $\mathrm{pH}$ values indicated a difference in nature of the precipitates.

For L-CNF, it took $1.25 \mathrm{~h}$ to reach the onset of precipitation at a pH of 6.4. Shortly afterward, the $\mathrm{pH}$ decreased to 6.3, the quasi-equilibrium found for L-un as well. Subsequently, the $\mathrm{pH}$ remained virtually constant and finally increased to 6.4 after $23 \mathrm{~h}$. The AAS measurements showed that at the starting $\mathrm{pH}, 0.45 \mathrm{wt} \%$ cobalt was already loaded on the CNF support. The amount of cobalt loading increased rapidly, and at the onset of precipitation after $1.25 \mathrm{~h}$, approximately $17 \%$ of cobalt had deposited, amounting to a $2.5 \mathrm{wt} \%$ loading. Once the maximum $\mathrm{pH}$ was reached, the deposition rate slowed, and even after $23 \mathrm{~h}$ not all cobalt had deposited; around $20 \%$ remained in solution, as indicated by the pink colour of the solution. The deposited cobalt was present not only on the CNF, but also on the glass parts of the setup. With AAS, the real cobalt loading on the support was determined to be $10.8 \mathrm{wt} \%$, demonstrating that the large majority of the precipitated cobalt was present on the support.

The longer time to the start of precipitation for L-CNF compared with L-un ( $1.25 \mathrm{~h}$ vs. $0.5 \mathrm{~h})$ could be due to the presence of acid sites on the activated CNF support, which from the start adsorb $\mathrm{Co}^{2+}$ and $\mathrm{CoOH}^{+}$ions. The AAS data demonstrated a substantial amount of cobalt loaded on the support (2.5 wt $\%)$ before the onset of precipitation. From the number of acidic oxygen groups on the surface $(0.42 \mathrm{mmol} / \mathrm{g})$, we calculated a loading of $2.5 \mathrm{wt} \%$ based on a one-to-one exchange ratio; thus it is possible that indeed the retarded $\mathrm{pH}$ increase is caused by the ion exchange of $\mathrm{Co}^{2+}$ in combination with or followed by hydroxylation. It is also possible that already in this stage, small cobalt hydroxide clusters are growing on the CNF support. This growth of metal hydroxide clusters before the precipitation onset was observed by van der Lee et al. in the preparation of $\mathrm{Ni} / \mathrm{CNF}$ using similar techniques [35]. The gradual growth of such small clusters retards the $\mathrm{pH}$ increase while loading cobalt on the support.

Shortly after the onset of precipitation at a $\mathrm{pH}$ of 6.4 , the $\mathrm{pH}$ dropped to 6.3, the quasi-equilibrium also found for L-un. Due to a lack of sufficient interaction with the CNF support, a cobalt precipitate was formed at $\mathrm{pH}$ values at which bulk precipitation is also possible. In what follows we demonstrate that these precipitates have the same composition.

\subsubsection{Investigation of dried samples}

The bulk precipitate L-un consisted of ordered rectangularshaped rods with lengths up to $2 \mu \mathrm{m}$ and aspect ratios of about 10 (Fig. 2A). The high-resolution TEM image in Fig. 2B shows that the rods were composed of ordered stacked layers with an 


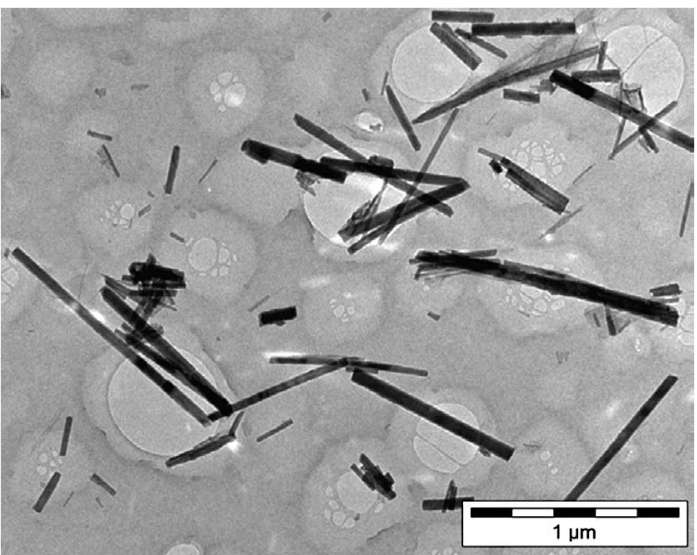

(A)

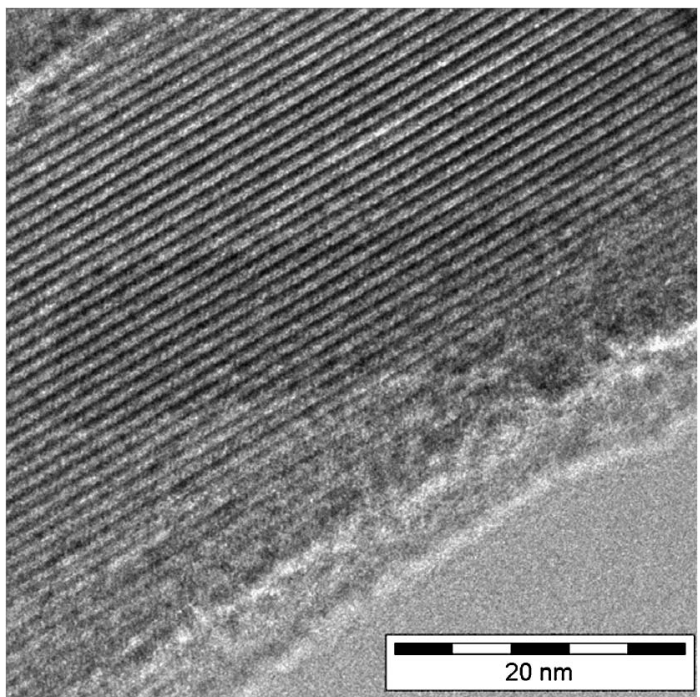

(B)

Fig. 2. TEM image of dried L-un with different sized rectangular rods (A) that consist of ordered stacked layers with a lattice spacing indicative of intercalated $\alpha-\mathrm{Co}(\mathrm{OH})_{2}(\mathrm{~B})$.

average lattice spacing of $0.94 \mathrm{~nm}$, a value characteristic of intercalated $\alpha-\mathrm{Co}(\mathrm{OH})_{2}[36,37]$. In our case, the intercalation of carbonate and/or ammonium ions was likely, because these are formed during the hydrolysis of urea [38]. The intercalation of carbonate in $\mathrm{Ni}(\mathrm{OH})_{2}$ during precipitation by means of urea hydrolysis was observed by Hermans et al. [21]. Using TGA-MS, we proved the presence of carbonate and small amounts of ammonia in L-un (data not shown).

A TEM image of dried L-CNF is given in Fig. 3. Cobalt seems to have precipitated in rectangular-shaped rods smaller in size than those obtained with L-un and often partly connected with the support. This suggests a rapid growth of the precipitate, hereby growing disconnected from the CNF. This may indicate that insufficient nucleation sites were available at the start of the growth process. In some cases, a cobalt precipitate was found next to the CNF support. Fig. 3 also indicates that a considerable part of the fibers had no detectable cobalt precipitate, pointing to the limited nucleation on the support.

The TEM image of dried $\mathrm{L}-S i O_{2}$ depicted in Fig. 4A shows aerosol particles $(\sim 20 \mathrm{~nm})$ and claylike structures $(8-80 \mathrm{~nm})$,

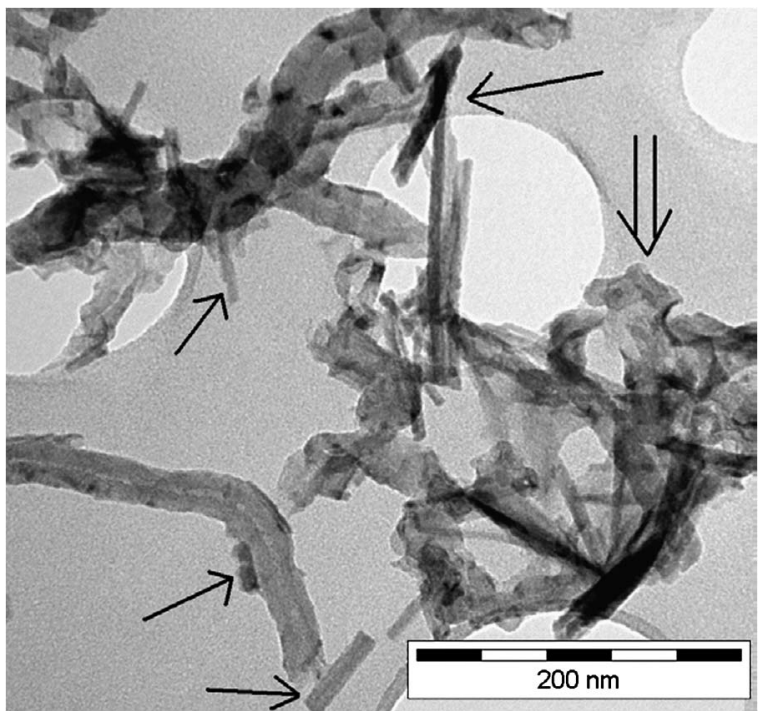

Fig. 3. TEM image of dried L-CNF with cobalt precipitated on the support (single arrows) and also unsupported cobalt (open arrow).

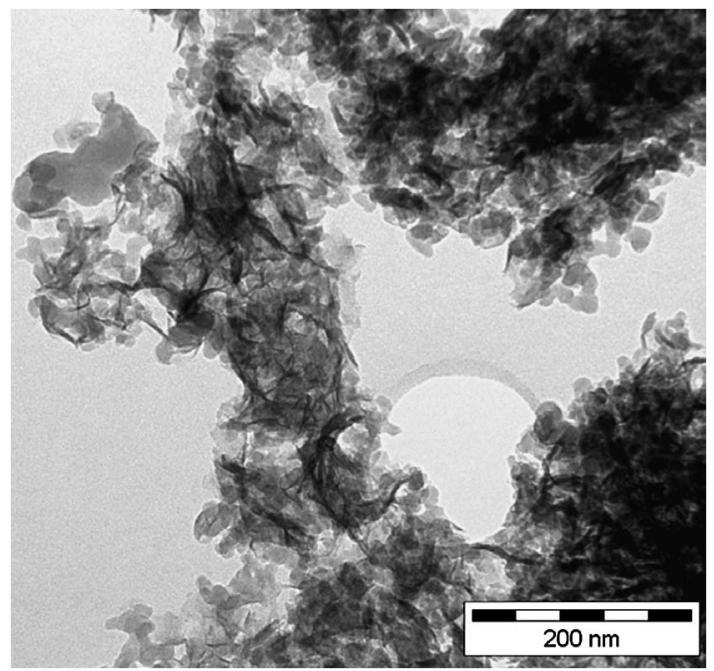

(A)

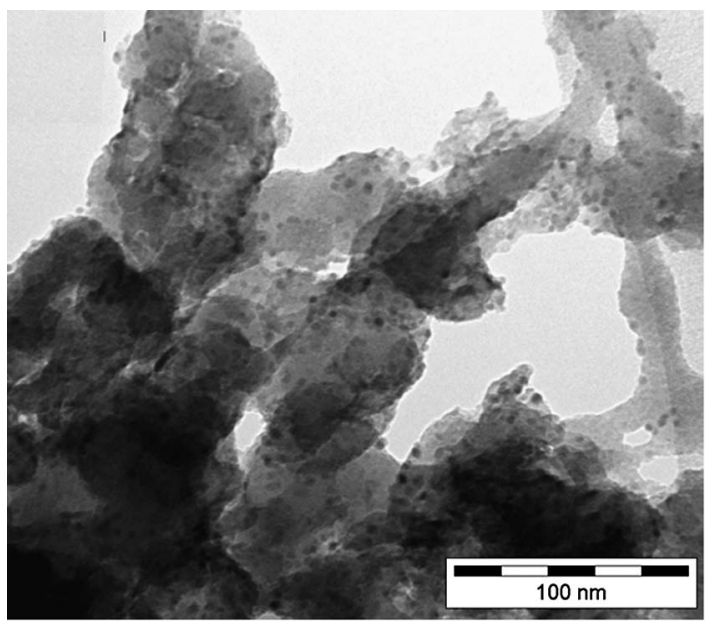

(B)

Fig. 4. TEM images of dried $\mathrm{L}_{-} \mathrm{SiO}_{2}$ showing clay-like structures typical for phyllosilicates (A). In some parts of the sample small cobalt particles can be observed (B). 


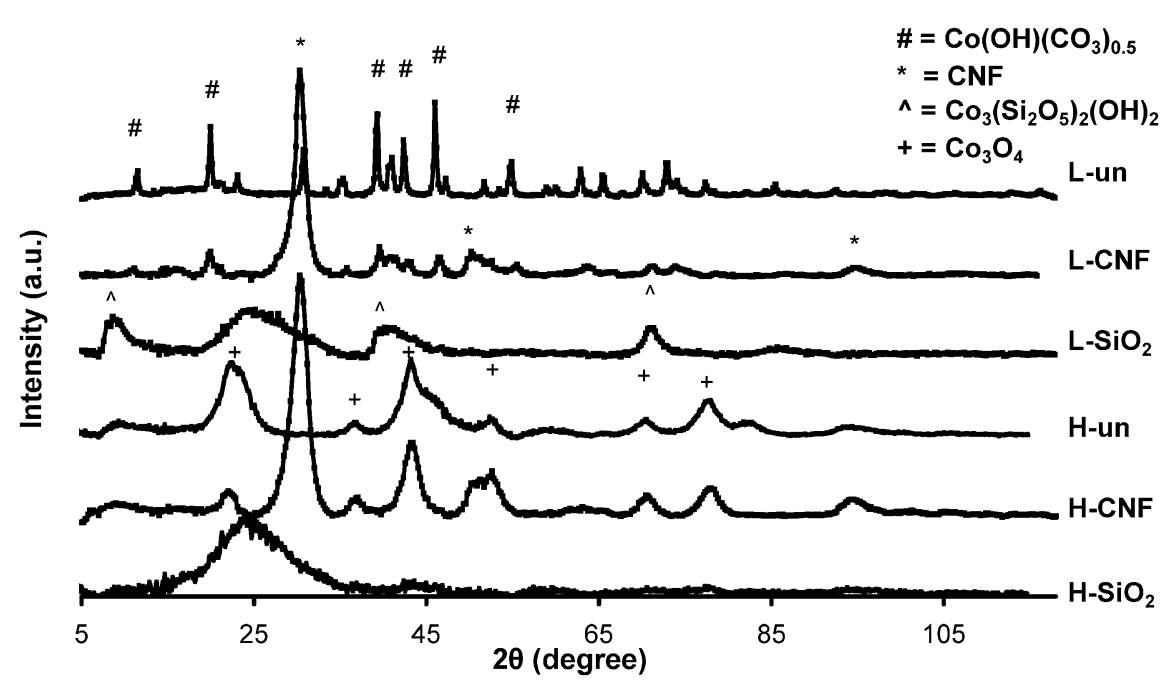

Fig. 5. XRD patterns of dried samples with strongest diffraction lines of main components indicated.

typical of phyllosilicates [20-23]. Obviously, silica reacted to a large extent with cobalt during the precipitation process. But TEM shows that in some parts of the sample, small particles with sizes varying from 2 to $5 \mathrm{~nm}$ were present in close contact with the support (Fig. 4B). TEM EDX demonstrated that these particles contained cobalt, but that only a small part of cobalt was present in this form. Most likely these particles consisted of some type of cobalt (hydroxy)carbonate, precipitated as small particles. Both types of cobalt species observed are in close contact with the support, in line with the conclusion drawn from the $\mathrm{pH}$-time curve.

XRD patterns of the dried samples are shown in Fig. 5, with the most pronounced diffraction lines of the main components indicated. The narrow line of L-un, indicative of large crystallites, can be attributed to a cobalt hydroxy carbonate: $\mathrm{Co}(\mathrm{OH})\left(\mathrm{CO}_{3}\right)_{0.5} \cdot 0.11 \mathrm{H}_{2} \mathrm{O}$ [39]. The precipitation of mixed carbonate hydroxides is thermodynamically more likely than the precipitation of pure cobalt hydroxide, as was calculated by Mostafa et al. [40]. For L-CNF, in addition to the graphitic lines, the three most intense diffraction lines of L-un, although somewhat broadened, are also observed. During synthesis, a similar type of cobalt compound was probably formed in the unsupported sample as for the CNF sample. The diffraction lines of $\mathrm{L}-\mathrm{SiO}_{2}$ are characteristic of cobalt hydrosilicates [41], whereas the absence of other diffraction lines also indicates that the largest fraction of cobalt was present as hydrosilicates, not as small cobalt hydroxy carbonate particles.

TPR profiles given in Fig. 6 show that the narrow reduction peak of L-un is located at $280^{\circ} \mathrm{C}$. A small reduction peak is present at around $200^{\circ} \mathrm{C}$, probably originating from the reduction of some urea contamination in the sample. Reduction of L-CNF started at the same temperature as reduction of L-un. But, probably due to the smaller particles of the precipitate, the reduction rate increased less steeply with temperature, and the peak position shifted to a somewhat higher temperature $\left(350^{\circ} \mathrm{C}\right)$. Furthermore, as gas chromatography analysis demonstrated, the broad shoulder at temperatures beyond $350^{\circ} \mathrm{C}$ must be ascribed to gasification of CNF to methane. For $\mathrm{L}_{-} \mathrm{SiO}_{2}$,

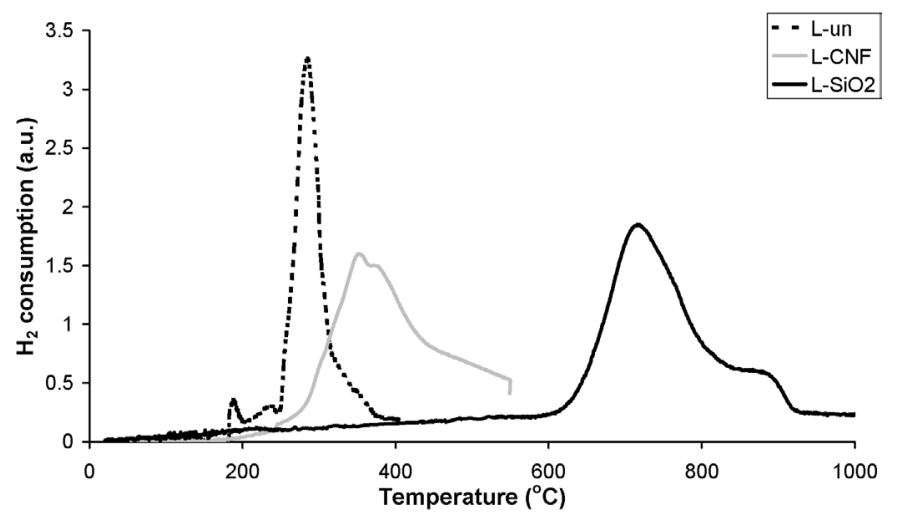

Fig. 6. TPR profiles normalized to the amount of cobalt for samples prepared from low $\mathrm{pH}$.

a high temperature reduction peak at $650{ }^{\circ} \mathrm{C}$ and a shoulder at $800^{\circ} \mathrm{C}$ are found that can be ascribed to the presence of cobalt(II) silicates [41]. From the hydrogen consumption, we could calculate that in $\mathrm{L}-\mathrm{SiO}_{2}$, cobalt was fully reduced at $900^{\circ} \mathrm{C}$.

\subsubsection{Investigation of reduced samples}

TEM analysis of L-CNF reduced at $350{ }^{\circ} \mathrm{C}$ showed cobalt particles with sizes varying from 4 to $100 \mathrm{~nm}$ (Fig. 7). The smaller particles are found throughout the whole sample and are always in close contact with the support (Figs. 7A and 7B). The largest particles, probably formed out of the large rods, have only limited interaction with the support. These large cobalt particles are black, surrounded by a greyish layer (Fig. 7B, arrows). This indicates that some reoxidation of metallic cobalt occurred when the sample was transferred from the reactor to the microscope. The cobalt oxide layer was about $3 \mathrm{~nm}$ thick, so particles smaller than $6 \mathrm{~nm}$ would be completely reoxidized by air after the reduction treatment. We estimated the average cobalt particle size as around $30 \mathrm{~nm}$, with a broad size distribution. The dispersion obtained from hydrogen chemisorption was $3.9 \%$, equivalent to an average particle size of $25 \mathrm{~nm}$. The XRD pattern of reduced and passivated L-CNF depicted in 


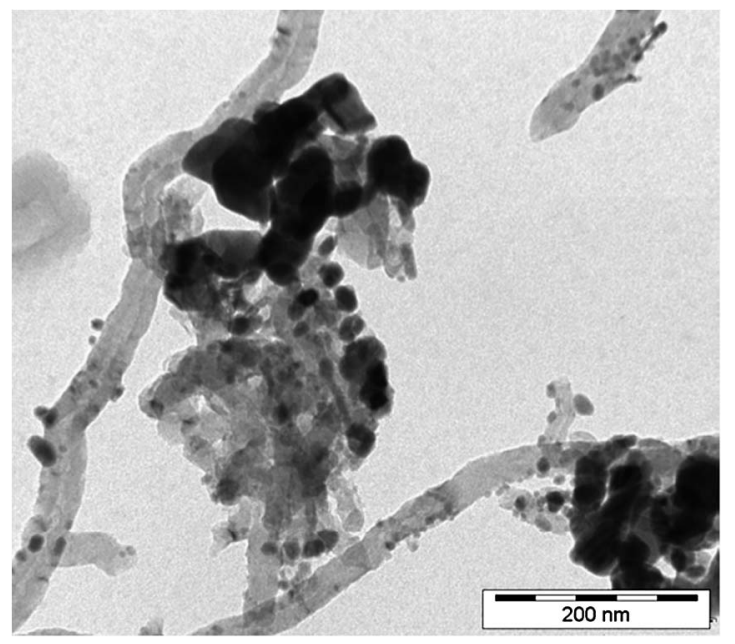

(A)

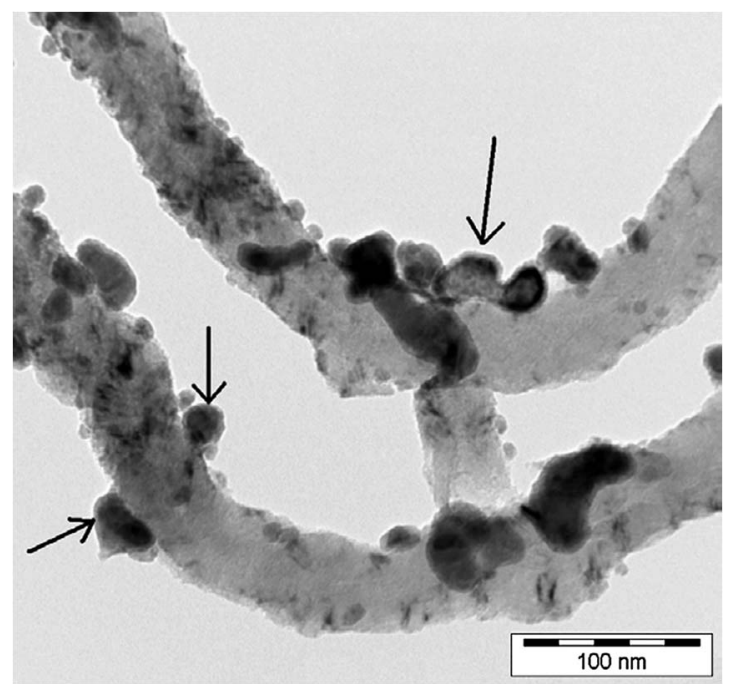

(B)

Fig. 7. TEM images of reduced L-CNF showing small supported cobalt particles together with larger particles with limited interaction with the support (A). Using a higher magnification around the black metallic core a grayish layer of $\mathrm{CoO}$ (arrows) can be observed (B).

Fig. 9 shows not only the characteristic diffractions of hexagonal metallic cobalt, but also the broad diffraction lines of cobalt oxide $(\mathrm{CoO})$.

TEM images of $\mathrm{L}_{-} \mathrm{SiO}_{2}$ reduced at $600^{\circ} \mathrm{C}$ show the presence of cobalt particles varying from 10 to $40 \mathrm{~nm}$ in size (Fig. 8). The average particle size, calculated by averaging over 150 particles, turned out to be $35 \mathrm{~nm}$. These results demonstrate that cobalt at the high reduction temperature is prone to sintering. Sintering was also evident from the difference in hydrogen uptake, measured with $\mathrm{H}_{2}$ chemisorption, after reductions at different temperatures. Table 2 gives apparent cobalt dispersions, assuming total reduction. Reduction at 400 and $500{ }^{\circ} \mathrm{C}$ produced only minimal hydrogen uptake; reduction at $600^{\circ} \mathrm{C}$ resulted in the highest uptake. Reduction at 700 or $900{ }^{\circ} \mathrm{C}$ resulted in slightly lower dispersions, indicating the modest sintering of cobalt at these high temperatures. The highest dispersion of $2.50 \%$ after reduction at $600{ }^{\circ} \mathrm{C}$ corresponds to cobalt particles of $40 \mathrm{~nm}$, confirming the TEM data. The XRD spectrum of the

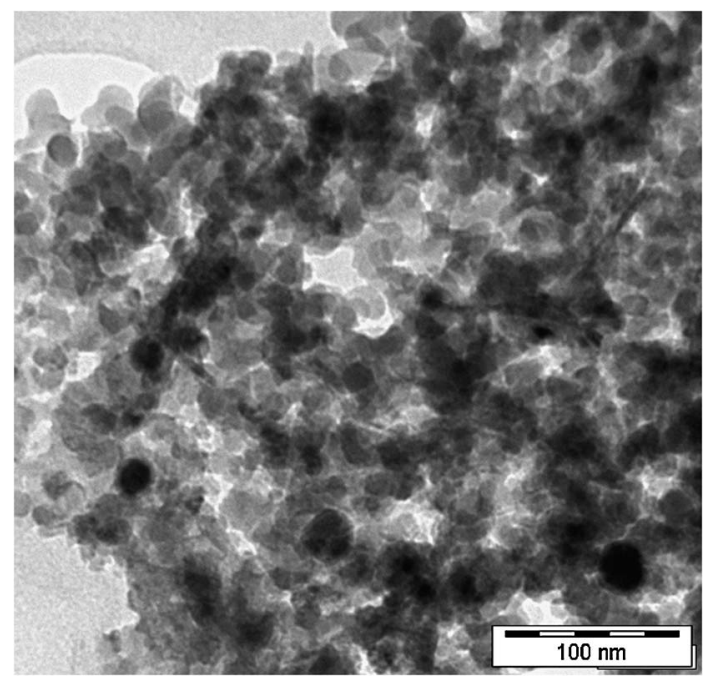

Fig. 8. TEM image of reduced $\mathrm{L}-\mathrm{SiO}_{2}$ with spherical $10-40 \mathrm{~nm}$ sized cobalt particles.

reduced and passivated ${\mathrm{L}-\mathrm{SiO}_{2}}_{2}$ sample displayed in Fig. 9 exhibits a weak, broad diffraction of $\mathrm{SiO}_{2}$ around $30^{\circ} 2 \theta$ together with cobalt oxide lines and stronger diffraction lines of metallic cobalt. The peaks at $49^{\circ}, 52^{\circ}$, and $56^{\circ} 2 \theta$ are indicative of the presence of hexagonal closed packed cobalt, but the diffraction line at $60^{\circ} 2 \theta$ in combination with a much higher-intensity line than expected at $52^{\circ} 2 \theta$ indicates that face-centred cubic cobalt is also present. Although hcp is the most stable structure for bulk cobalt at room temperature the fcc structure is reported to be the main phase in some cases, especially on oxidic supports [33].

The difference in final metal particle size between L-CNF and $\mathrm{L}-\mathrm{SiO}_{2}$ can be rationalized if both the dispersion of the dried catalyst precursor and the required reduction temperatures (Figs. 6 and 14) are taken into account. The cobalt phase present in $\mathrm{L}_{-} \mathrm{SiO}_{2}$ before reduction was highly dispersed, but the high reduction temperature caused sintering of cobalt, resulting in a final catalyst with 40-nm cobalt particles. The dispersion of the cobalt precursor was lower in dried L-CNF than in dried L$\mathrm{SiO}_{2}$; however, the lower reduction temperature did not result in cobalt sintering, ending up with a final catalyst with an average cobalt particle size of $25 \mathrm{~nm}$.

\subsection{Precipitation starting from high $\mathrm{pH}$}

\subsubsection{Observations during preparation and analysis of $\mathrm{pH}$ curves}

The solutions were transparent dark-red at the starting $\mathrm{pH}$ $(\sim 11)$ due to the presence of $\mathrm{Co}\left(\mathrm{NH}_{3}\right)_{6}{ }^{2+}$. During the process, the solution colour changed first to orange and then to purple. Subsequently the solutions gradually decolorized, indicating that cobalt had completely precipitated. Unsupported and silicasupported precipitates were dark brown. In all systems the $\mathrm{pH}$ dropped rapidly over the first $30 \mathrm{~min}$, due to both the temperature increase and the rapid evaporation of ammonia. As shown in Fig. 10A, the courses of the $\mathrm{pH}$ curves are rather similar, with some discontinuities reflecting the influence of the precipitation 


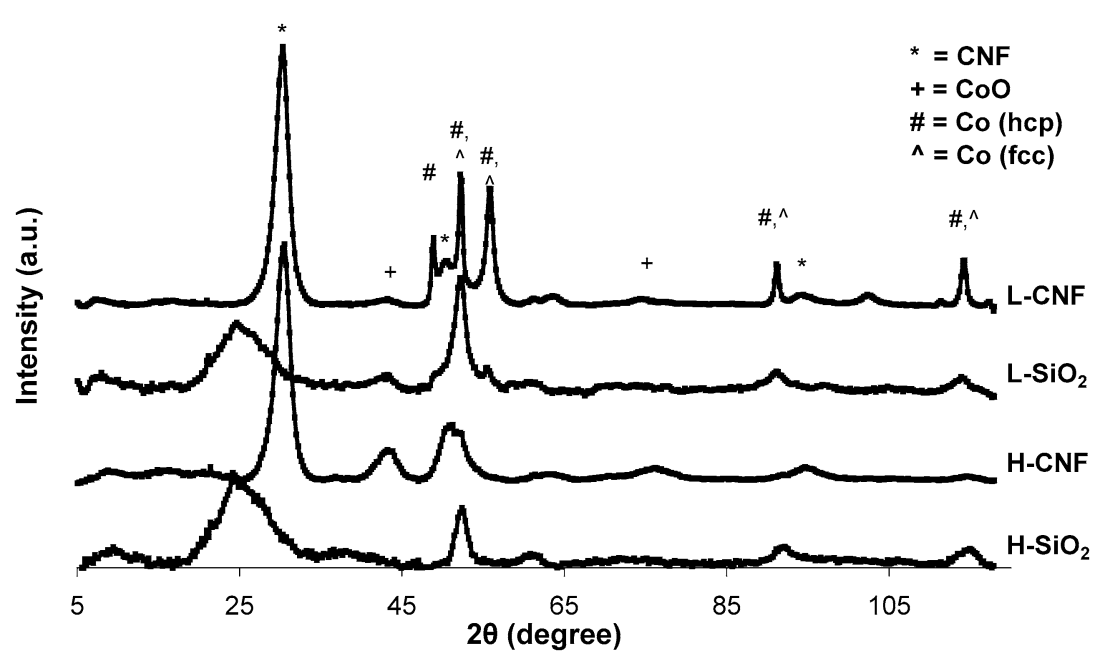

Fig. 9. XRD patterns of reduced and passivated samples with the strongest diffraction lines of the main components indicated.
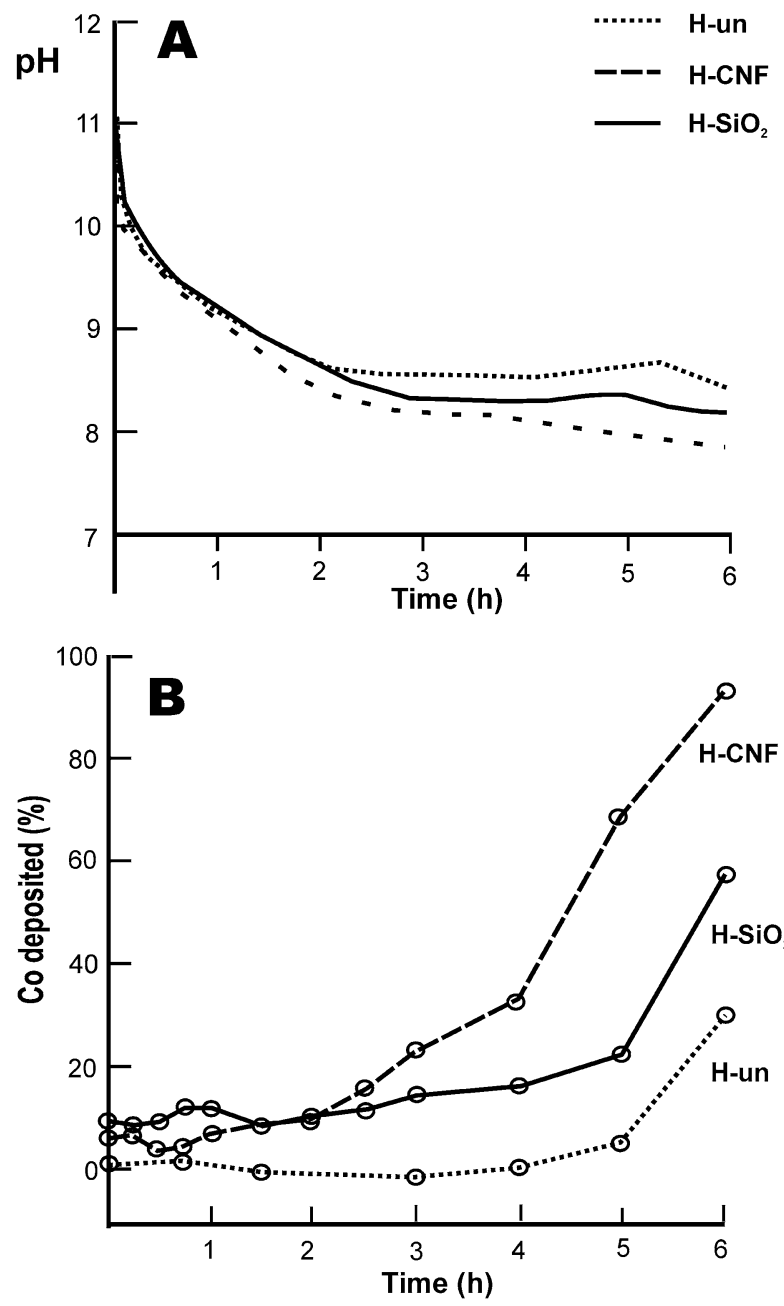

Fig. 10. $\mathrm{pH}$ curves during precipitation from high $\mathrm{pH}(\mathrm{A})$ with corresponding cobalt deposition as function of deposition time (B).

process. The most unambiguous observation from the $\mathrm{pH}$-time experiments is that at corresponding times, the $\mathrm{pH}$ was significantly lower when a support was present. This could indicate that cobalt did not precipitate on the support, because precipitation at higher $\mathrm{pH}$ values than for bulk precipitation is expected for the formation of a precipitate in strong interaction with the support. However, analysis of the precipitates clearly indicated that cobalt precipitated exclusively on the support for both $\mathrm{H}$ $\mathrm{CNF}$ and $\mathrm{H}-\mathrm{SiO}_{2}$. This demonstrates that $\mathrm{pH}$ measurements during precipitation starting from basic solution are not conclusive with respect to the nature of the precipitation process. Evaluation of precipitation can be done only when the information of the $\mathrm{pH}$-time curves is combined with information from the Co deposition measured with AAS.

\subsubsection{Extent of cobalt deposition in time}

Fig. 10B shows the cobalt fraction deposited as a function of time for the three experiments. With H-un, the deposited cobalt fraction remained negligible up to at least $5 \mathrm{~h}$, and nucleation most likely started after the shallow $\mathrm{pH}$ overshoot at that time (Fig. 10A). With $\mathrm{H}-\mathrm{SiO}_{2}$ and $\mathrm{H}-\mathrm{CNF}$, cobalt had adsorbed already at the start, and during the experiment the amounts precipitated on the supports remained larger, indicating the facilitated surface precipitation. At the start of the experiment, $8-10 \%$ of the total amount of cobalt was adsorbed on the support, coinciding nicely with the loadings measured with samples separately prepared by ion adsorption.

An increased rate of Co deposition on CNF was measured after $2 \mathrm{~h}$ at a $\mathrm{pH}$ of 8.5 , indicated by the steeper slope of the deposition curve. A further acceleration of the rate of precipitation was measured after $4 \mathrm{~h}$, resulting in almost complete removal of Co from the solution over the next $2 \mathrm{~h}$. With silica as the support, a slightly enhanced rate of precipitation was observed after around $3 \mathrm{~h}$, with a more significant acceleration seen after around $4 \mathrm{~h}$. In both cases this was accompanied first by stabilization of the $\mathrm{pH}$, followed by a further decrease in $\mathrm{pH}$. This $\mathrm{pH}$ stabilization likely was caused by the production of $\mathrm{NH}_{3}$ from the ligand exchange in the ammonia complex.

\subsubsection{Investigation of dried samples}

With H-un, cobalt had precipitated in particles with a size of about $5 \mathrm{~nm}$, clustered together to units up to a few hundred $\mathrm{nm}$ (Fig. 11). The XRD pattern of dried H-un, depicted in Fig. 5, is typical of that for $\mathrm{Co}_{3} \mathrm{O}_{4}$ with broadened line shapes, indicat- 


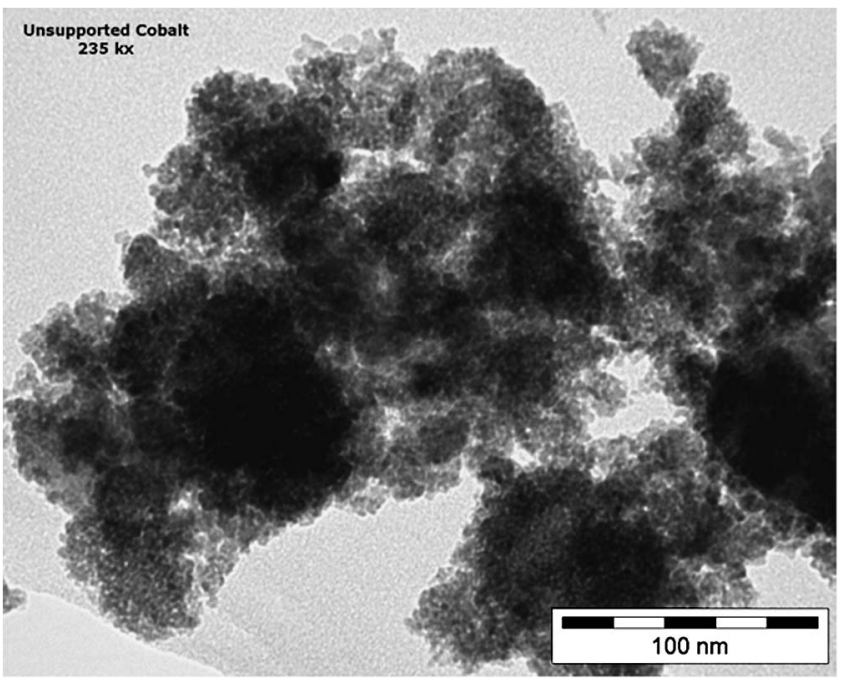

Fig. 11. TEM image of dried $\mathrm{H}$-un showing that cobalt precipitated in clusters of a few hundred nm that consist of sub units of $5 \mathrm{~nm}$.

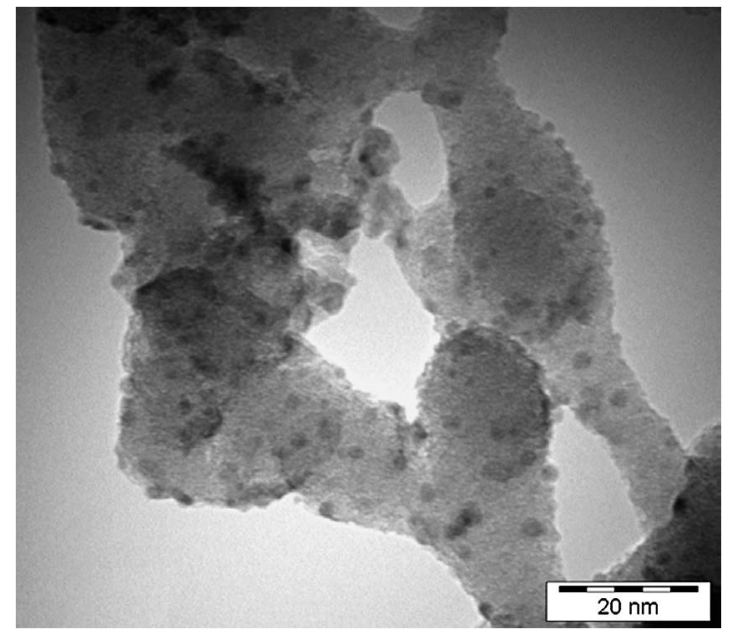

Fig. 12. TEM image of dried $\mathrm{H}-\mathrm{SiO}_{2}$ with small, evenly distributed cobalt particles.

ing the presence of particles of around $5 \mathrm{~nm}$. Because the direct deposition of $\mathrm{Co}_{3} \mathrm{O}_{4}$ is not feasible from the $\mathrm{Co}^{2+}$ solution, this compound was formed during aging either in the solution or in the drying step. In experiments that were stopped before the final $\mathrm{pH}$ was reached (data not shown), we observed very distinct patterns from $\left(\mathrm{NH}_{4}\right)_{2} \mathrm{Co}_{8}\left(\mathrm{CO}_{3}\right)_{6}(\mathrm{OH})_{6}\left(\mathrm{H}_{2} \mathrm{O}\right)_{4}$ [42], although superpositioned on broad diffraction lines of $\mathrm{Co}_{3} \mathrm{O}_{4}$. We propose that the initial cobalt phase deposited was largely $\left(\mathrm{NH}_{4}\right)_{2} \mathrm{Co}_{8}\left(\mathrm{CO}_{3}\right)_{6}(\mathrm{OH})_{6}\left(\mathrm{H}_{2} \mathrm{O}\right)_{4}$, which was further oxidized to $\mathrm{Co}_{3} \mathrm{O}_{4}$ during aging and drying.

The initial $\left(\mathrm{NH}_{4}\right)_{2} \mathrm{Co}_{8}\left(\mathrm{CO}_{3}\right)_{6}(\mathrm{OH})_{6}\left(\mathrm{H}_{2} \mathrm{O}\right)_{4}$ phase in $\mathrm{H}$-un was different from that obtained with L-un (i.e., $\mathrm{Co}(\mathrm{OH})$ $\left.\left(\mathrm{CO}_{3}\right)_{0.5} \cdot 0.11 \mathrm{H}_{2} \mathrm{O}\right)$. When comparing the TEM images, the difference in crystallite size of $\mathrm{H}$-un and L-un stands out. Clearly, on supersaturation at high $\mathrm{pH}$, more nuclei were formed and/or nuclei growth was slower. An explanation for this could be the higher ionic strength with H-un, which decreases the activation energy for nuclei formation $[43,44]$.

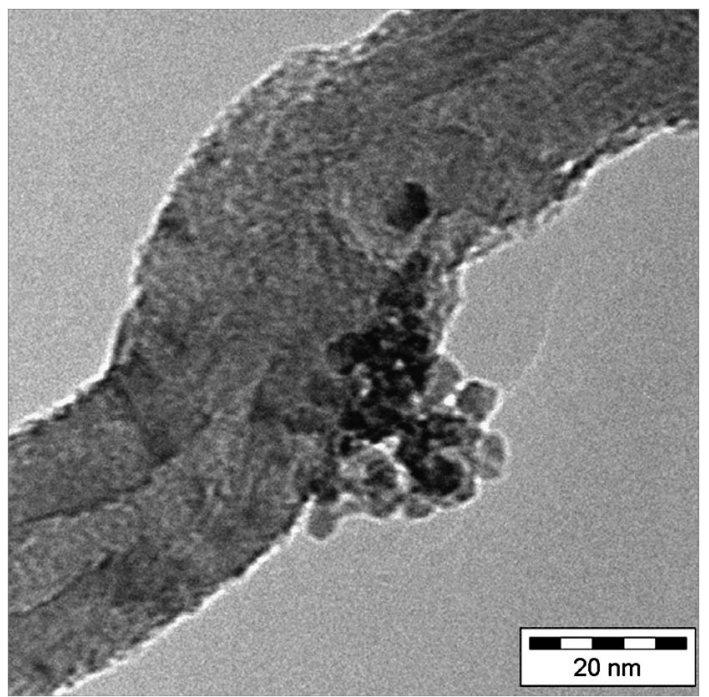

Fig. 13. TEM image of dried H-CNF showing an individual carbon nanofiber with a bunch-like cobalt precipitate.

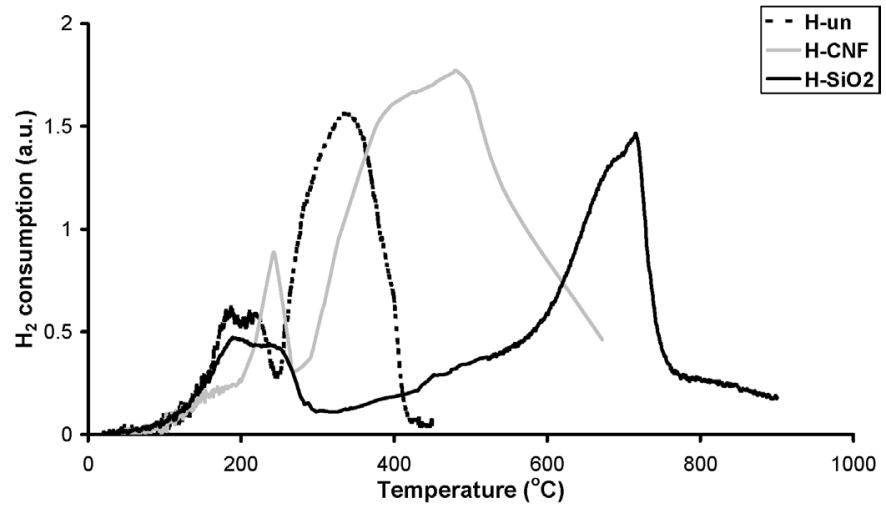

Fig. 14. TPR profiles normalized to the amount of cobalt for samples prepared from high $\mathrm{pH}$.

In Figs. 12 and 13, supported cobalt particles are apparent on both $\mathrm{H}-\mathrm{SiO}_{2}$ and $\mathrm{H}-\mathrm{CNF}$. As we concluded based on the AAS measurements and the $\mathrm{pH}$-time curves, no precipitation separate from the support was found not only with $\mathrm{H}-\mathrm{SiO}_{2}$, but also with $\mathrm{H}-\mathrm{CNF}$. For $\mathrm{H}-\mathrm{SiO}_{2}$, the cobalt particles are around $5 \mathrm{~nm}$ (Fig. 12). With TEM, we found no indication of plate-like hydrosilicates dissimilar to $\mathrm{L}-\mathrm{SiO}_{2}$. XRD of $\mathrm{H}-\mathrm{SiO}_{2}$ showed broad diffraction lines, complicating assignment (Fig. 5). Apart from the silica band, weak and broad contributions of $\mathrm{Co}_{3} \mathrm{O}_{4}$ were present, in line with the 5-nm particles observed on TEM. A TEM image of dried H-CNF revealed that cobalt had deposited onto the surface of the fiber as clusters consisting of 5-nm particles (Fig. 13). The bunch-like shape of the precipitate in both $\mathrm{H}$-un and $\mathrm{H}-\mathrm{CNF}$ indicates that the precipitation was not a single nucleation followed by growth process, but rather that new nuclei were formed at the surface of particles.

However, TEM analysis (Fig. 13) also showed that a considerable part of the fibers was not covered with particles. This suggests that nucleation had occurred only in certain places on the fibers; that is, the critical density of adsorbed cobalt ions had been reached. Toebes et al. showed that after reflux in ni- 
tric acid for $2 \mathrm{~h}$, the density of carboxylic groups on CNF was about $0.42 \mathrm{mmol} / \mathrm{g}$ [32]; however, these groups likely were not evenly distributed over the surface. In regions with a high density of carboxylic groups, the concentration of adsorbed cobalt ions might become high enough to facilitate nucleation at the surface. Subsequent growth of the nuclei and formation of new nuclei on the fresh crystals finally results in the grape-like morphology of the precipitate. This can also explain why H-CNF showed a better cobalt dispersion than L-CNF. The 2.5 times higher concentration of adsorbed cobalt ions for $\mathrm{H}-\mathrm{CNF}$ makes more nucleation sites available, resulting in a smaller cobalt particle size after reduction. XRD of dried H-CNF (Fig. 5) showed the characteristic graphite diffraction lines and cobalt diffraction lines at positions typical for $\mathrm{Co}_{3} \mathrm{O}_{4}$.

TPR profiles in Fig. 14 show that $\mathrm{H}$-un exhibited a reduction peak at $330^{\circ} \mathrm{C}$, somewhat higher than that obtained with L-un. This shift to higher temperature might be related to the smaller size of the H-un crystallites. The peak at around $180-210^{\circ} \mathrm{C}$ can be ascribed to the reduction of $\mathrm{Co}_{3} \mathrm{O}_{4}$ to $\mathrm{CoO}$.

$\mathrm{H}-\mathrm{SiO}_{2}$ shows an early reduction peak at $200{ }^{\circ} \mathrm{C}$, probably due to the reduction of cobalt $\mathrm{Co}^{3+}$ to $\mathrm{Co}^{2+}$, and a very broad reduction peak starting at $410^{\circ} \mathrm{C}$ and extending to above $700^{\circ} \mathrm{C}$, which can be ascribed to the reduction of small $\mathrm{CoO}$ particles and cobalt(II) silicates. Although platelets of hydrosilicates were not indicated on XRD and TEM, in situ formation of cobalt silicates are possibly during reduction. Compared with $\mathrm{L}-\mathrm{SiO}_{2}, \mathrm{H}-\mathrm{SiO}_{2}$ had a main reduction peak at the same temperature $\left(700^{\circ} \mathrm{C}\right)$ but had an onset of reduction $150^{\circ} \mathrm{C}$ earlier and also returned more steeply to the baseline. The degree of reduction for $\mathrm{H}-\mathrm{SiO}_{2}$ calculated from the amount of $\mathrm{H}_{2}$ consumed during the TPR experiment was $95 \%$.

In the reduction profile of $\mathrm{H}-\mathrm{CNF}$, two distinct stages exist: the reduction of $\mathrm{Co}^{3+}$ to $\mathrm{Co}^{2+}$ with a peak at $240^{\circ} \mathrm{C}$, and the reduction of $\mathrm{Co}^{2+}$ to $\mathrm{Co}^{0}$ beyond $270^{\circ} \mathrm{C}$ with a maximum at $400^{\circ} \mathrm{C}$, which overlaps with the gasification of the carbon fibers. Gasification started as soon as metal was formed in close contact with the support. More metal particles were in close contact with the support with H-CNF than with L-CNF, due to the more rapid gasification. Taking into account the cobalt loading and oxidation state, we calculated that one-third of the area of the second peak can be attributed to the consumption of hydrogen in this gasification step.

\subsubsection{Investigation of reduced samples}

TEM found metallic cobalt clusters of around $20 \mathrm{~nm}$ with $\mathrm{H}-\mathrm{SiO}_{2}$ reduced at $500^{\circ} \mathrm{C}$ (data not shown). Apparently some sintering had taken place during reduction, but not as much as was observed with $\mathrm{L}-\mathrm{SiO}_{2}$. The XRD pattern of reduced and passivated $\mathrm{H}-\mathrm{SiO}_{2}$, depicted in Fig. 9, also shows diffraction lines similar to that of $\mathrm{L}_{-} \mathrm{SiO}_{2}$, stemming from a mixture of $\mathrm{CoO}$ and fcc and hep metallic cobalt. The dispersion of the catalyst was also measured using $\mathrm{H}_{2}$ chemisorption. Table 2 gives the cobalt dispersions (assuming complete reduction) as a function of reduction temperature. Already after reduction at $400^{\circ} \mathrm{C}$, a large fraction of the cobalt had been reduced. With $\mathrm{H}-$ $\mathrm{SiO}_{2}$, the highest dispersion of $7.3 \%$, found after reduction at $500{ }^{\circ} \mathrm{C}$, is equivalent to a cobalt particle size of $13 \mathrm{~nm}$. Higher

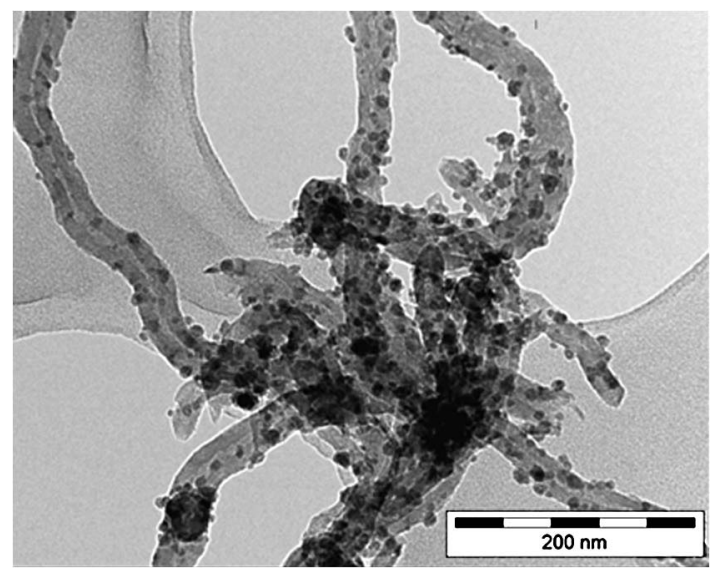

(A)

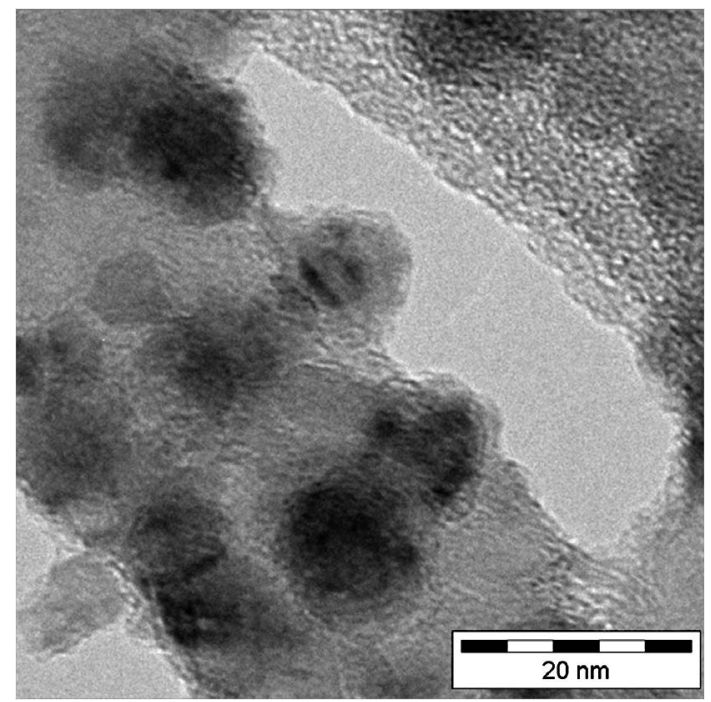

(B)

Fig. 15. TEM images of reduced and passivated $\mathrm{H}-\mathrm{CNF}$ showing almost spherical, partly re-oxidized cobalt particles distributed over the carbon nanofibers at (A) medium resolution and (B) high resolution.

reduction temperatures resulted in modest sintering, as was observed for $\mathrm{L}-\mathrm{SiO}_{2}$.

Two representative TEM images of reduced H-CNF are shown in Figs. 15A and 15B. From the first figure, it is clear that cobalt was nicely dispersed over the CNF surface. The particle size is around $10 \mathrm{~nm}$, with a narrow particle size distribution. The high-resolution image in Fig. 15B shows that the particles are spherical with a dark core and a more greyish shell. The dark core is metallic cobalt, whereas the outer layer of about $4 \mathrm{~nm}$ is oxidised by air, forming an expanded and amorphous $\mathrm{CoO}$ layer with lower contrast. The XRD pattern of reduced and passivated $\mathrm{H}-\mathrm{CNF}$ in Fig. 9 shows strong $\mathrm{CoO}$ diffraction lines and broad metallic lines for fcc cobalt.

The cobalt particle size as measured by $\mathrm{H}_{2}$ chemisorption of $\mathrm{H}$-CNF was $8 \mathrm{~nm}$ (Table 1). This is in close agreement with the $10 \mathrm{~nm}$ size found with TEM taking into account the contraction of $\mathrm{CoO}$ to $\mathrm{Co}(25 \%)$ during reduction.

It is interesting to note that although we found a higher dispersion of the cobalt precursor in dried $\mathrm{H}-\mathrm{SiO}_{2}$ than in dried $\mathrm{H}-\mathrm{CNF}$, the situation is opposite after reduction. The higher 
Table 3

Performance of catalysts in the FT reaction after reduction for $2 \mathrm{~h}$ at $350{ }^{\circ} \mathrm{C}$ (L-CNF, $\mathrm{H}-\mathrm{CNF}), 500^{\circ} \mathrm{C}\left(\mathrm{H}_{-} \mathrm{SiO}_{2}\right)$ or $600^{\circ} \mathrm{C}\left(\mathrm{L}_{-} \mathrm{SiO}_{2}\right)$

\begin{tabular}{llllll}
\hline Sample & $\begin{array}{l}\text { Cobalt size } \\
(\mathrm{nm})\end{array}$ & Activity $^{\mathrm{a}}$ & $\mathrm{TOF}^{\mathrm{b}}$ & $\begin{array}{l}\mathrm{C}_{1} \\
(\mathrm{wt} \%)\end{array}$ & $\begin{array}{l}\mathrm{C}_{5+} \\
(\mathrm{wt} \%)\end{array}$ \\
\hline $\mathrm{L}-\mathrm{CNF}$ & 25 & 0.64 & 9.7 & 40 & 23 \\
$\mathrm{H}-\mathrm{CNF}$ & 7.9 & 1.24 & 6.0 & 20 & 53 \\
$\mathrm{~L}_{-} \mathrm{SiO}_{2}$ & 40 & 0.35 & 8.3 & 40 & 23 \\
$\mathrm{H}^{-\mathrm{SiO}_{2}}$ & 13 & 1.31 & 10.6 & 42 & 21 \\
\hline
\end{tabular}

Note. Conditions: 1 bar, $\mathrm{H}_{2} / \mathrm{CO}=2,220^{\circ} \mathrm{C}, 2 \%$ conversion of $\mathrm{CO}$.

${ }^{a}$ Normalized activity: $10^{-5} \mathrm{~mol}_{\mathrm{CO}} /\left(\mathrm{g}_{\mathrm{Co}} \mathrm{s}\right)$.

b TOF: $10^{-3} \mathrm{~s}^{-1}$ based on dispersion $\mathrm{H}_{2}$ chemisorption.

reduction temperature needed for $\mathrm{H}-\mathrm{SiO}_{2}$ caused sintering of cobalt, resulting in a final catalyst with an average cobalt particle size of $15 \mathrm{~nm}$, whereas for H-CNF, sintering was not apparent with an average cobalt metal particle size of $8 \mathrm{~nm}$. Likewise, the higher dispersion of $\mathrm{H}-\mathrm{SiO}_{2}$ compared with $\mathrm{L}-\mathrm{SiO}_{2}$ can also be related to the catalyst precursor and the required reduction temperatures. The $\mathrm{Co}_{3} \mathrm{O}_{4}$ phase in $\mathrm{H}-\mathrm{SiO}_{2}$ could be reduced at a lower temperature than the cobalt hydrosilicate phase in L$\mathrm{SiO}_{2}$, resulting in better dispersion. The last comparison to be made is between L-CNF and H-CNF. Because of higher cobalt ion adsorption before deposition on H-CNF compared with L$\mathrm{CNF}$, nucleation occurred selectively on the CNF surface, and smaller cobalt precursor particles were formed that did not sinter on the mild reduction at $350^{\circ} \mathrm{C}$.

\subsubsection{Catalytic data}

The different catalysts were tested for their performance in the Fischer-Tropsch reaction (Table 3). The catalysts prepared using precipitation starting at high $\mathrm{pH}$ outperformed the catalysts prepared in acidic solution. For the silica-supported catalysts, the activity increased fourfold going from $\mathrm{L}-\mathrm{SiO}_{2}$ to $\mathrm{H}-\mathrm{SiO}_{2}$, while the selectivity remained virtually the same. In addition, for the CNF-supported catalysts, the activity for $\mathrm{H}-$ $\mathrm{CNF}$ was twice that for L-CNF. The methane selectivity of $\mathrm{H}-\mathrm{CNF}$ was only $20 \mathrm{wt} \%$, whereas the $\mathrm{C}_{5+}$ selectivity was as high as $53 \mathrm{wt} \%$, values characteristic of promoted catalysts [10]. Likely related to this high selectivity was the quite low specific activity (TOF) of this catalyst; however, more research is needed to explain this observation.

\section{Conclusion}

Using the classical HDP method with urea decomposition to slowly increase the $\mathrm{pH}$ from acidic to neutral, a $15 \mathrm{wt} \%$ catalyst on silica was prepared. A strong interaction between the cobalt species and the silica was found, resulting in a sample consisting mainly of cobalt hydrosilicates. The formed compound was highly stable, and it turned out to be fully reducible only at around $600^{\circ} \mathrm{C}$, at which temperature the formed metal particles sintered to $35 \mathrm{~nm}$. Using an HDP method with ammonia evaporation to decrease the $\mathrm{pH}$, a cobalt carbonate compound precipitated with less interaction with the silica, present as $4 \mathrm{~nm}$ particles in the dried sample. A lower reduction temperature of $500^{\circ} \mathrm{C}$ was sufficient to attain complete reduction, resulting in a silica-supported catalyst with 13-nm cobalt particles.
With CNF as the support material, activated by treatment in nitric acid, adsorption of Co species in acidic solution on the mainly carboxylic oxygen groups appeared to be too small to achieve selective nucleation on the support. Because of this too-low interaction, a catalyst with a cobalt metal dispersion of only $3.9 \%$ was obtained. A stronger interaction was found for the sample prepared from high $\mathrm{pH}$. Now the cobalt precursor selectively precipitated on the support, resulting in a catalyst with a cobalt metal dispersion of $12 \%$ after reduction at $350^{\circ} \mathrm{C}$. Precipitation at high $\mathrm{pH}$ produced a 2.3 times greater cobalt ion adsorption on the CNF surface. For the H-CNF sample, both prerequisites for preparation of highly dispersed catalysts with HDP-(1) sufficient interaction in the aqueous phase to achieve nucleation exclusively on the support surface and (2) modest interaction in the solid phase to facilitate reduction of the catalyst at low temperatures-were fulfilled. The cobalt hydroxy carbonate precipitate was reducible at a relatively low temperature, thus avoiding sintering, killing two birds with one stone.

Catalytic tests showed that catalysts prepared from high $\mathrm{pH}$ outperformed the catalysts prepared from low $\mathrm{pH}$. Depending on the support material, the activity increased by a factor of between 2 and 4 . Remarkably high and stable $\mathrm{C}_{5+}$ selectivity of around $53 \mathrm{wt} \%$ was found for H-CNF catalyst, demonstrating the good prospects for Fischer-Tropsch reaction of both the synthesis route and the support material.

\section{Acknowledgments}

The authors thank A. van der Eerden for the XRF data, A. Broersma for the TGA-MS data, and M. Versluis-Helder for the XRD data. Financial support was provided by Shell Global Solutions International.

\section{References}

[1] P.J. van Berge, J. van de Loosdrecht, S. Barradas, A.M. van der Kraan, Catal. Today 58 (2000) 321.

[2] J.L. Li, G. Jacobs, T. Das, Y.Q. Zhang, B. Davis, Appl. Catal. A 236 (2002) 67.

[3] X. Qiu, N. Tsubaki, S. Sun, K. Fujimoto, Catal. Commun. 2 (2001) 75.

[4] S.L. Sun, N. Tsubaki, K. Fujimoto, Appl. Catal. A: Gen. 202 (2000) 121.

[5] C. Moreno-Castilla, F. Carrasco-Marin, J. Chem. Soc., Faraday Trans. 91 (1995) 3519.

[6] R.C. Reuel, C.H. Bartholomew, J. Catal. 85 (1984) 78.

[7] K.P. de Jong, J.W. Geus, Catal. Rev.-Sci. Eng. 42 (2000) 481

[8] P. Serp, M. Corrias, P. Kalck, Appl. Catal. A 253 (2003) 337.

[9] G.L. Bezemer, A. van Laak, A.J. van Dillen, K.P. de Jong, Stud. Surf. Sci. Catal. 147 (2004) 259

[10] G.L. Bezemer, U. Falke, A.J. van Dillen, K.P. de Jong, Chem. Commun. (2005) 701.

[11] M.L. Toebes, F.F. Prinsloo, J.H. Bitter, A.J. van Dillen, K.P. de Jong, J. Catal. 214 (2003) 78.

[12] N. Spanos, L. Vordonis, C. Kordulis, A. Lycourghiotis, J. Catal. 124 (1990) 301.

[13] O. Clause, M. Kermarec, L. Bonneviot, F. Villain, M. Che, J. Am. Chem. Soc. 114 (1992) 4709.

[14] W.A. Spieker, J.R. Regalbuto, Chem. Eng. Sci. 56 (2001) 3491.

[15] J.R. Regalbuto, M. Schrier, X. Hao, W.A. Spieker, J.G. Kim, J.T. Miller, A.J. Kropf, Stud. Surf. Sci. Catal. (2002) 45. 
[16] A.J. van Dillen, R. Terorde, D.J. Lensveld, J.W. Geus, K.P. de Jong, J. Catal. 216 (2003) 257.

[17] J.A. Bergwerff, T. Visser, B.R.G. Leliveld, B.D. Rossenaar, K.P. de Jong, B.M. Weckhuysen, J. Am. Chem. Soc. 126 (2004) 14548.

[18] A. Lekhal, B.J. Glasser, J.G. Khinast, Chem. Eng. Sci. 56 (2001) 4473.

[19] E. Iglesia, Appl. Catal. A 161 (1997) 59.

[20] A.J. van Dillen, J.W. Geus, L.A.M. Hermans, J. van der Meijden, Proc. 6th Int. Congr. Catal. 2 (1977) 677.

[21] L.A.M. Hermans, J.W. Geus, Stud. Surf. Sci. Catal. 3 (1979) 113.

[22] P. Burattin, M. Che, C. Louis, J. Phys. Chem. B 102 (1998) 2722.

[23] P. Burattin, M. Che, C. Louis, J. Phys. Chem. B 101 (1997) 7060.

[24] K.P. de Jong, Stud. Surf. Sci. Catal. 63 (1991) 19.

[25] P. Burattin, M. Che, C. Louis, J. Phys. Chem. B 103 (1999) 6171.

[26] M. Keyser, F.F. Prinsloo, Carbon'01, Int. Conf. on Carbon, Lexington, KY, United States, 14-19 July 2001, p. 1206.

[27] F.F. Prinsloo, D. Hauman, R. Slabbert, Carbon'01, Int. Conf. on Carbon, Lexington, KY, United States, 14-19 July 2001, p. 940.

[28] J.H. Bitter, M.K. van der Lee, A.G.T. Slotboom, A.J. van Dillen, K.P. de Jong, Catal. Lett. 89 (2003) 139.

[29] R.L.C. Bonne, C.M. Lok, WO Patent 9604072 (1996), to Crosfield Joseph $\&$ Sons.

[30] C.M. Lok, Stud. Surf. Sci. Catal. 147 (2004) 283
[31] M.L. Toebes, J.H. Bitter, A.J. van Dillen, K.P. de Jong, Catal. Today 76 (2002) 33.

[32] M.L. Toebes, J.M.P. van Heeswijk, J.H. Bitter, A.J. van Dillen, K.P. de Jong, Carbon 42 (2004) 307.

[33] R.C. Reuel, C.H. Bartholomew, J. Catal. 85 (1984) 63.

[34] C.F. Baes, R.E. Mesmer, The Hydrolysis of Cations, Wiley, New York, 1976, p. 240.

[35] M.K. van der Lee, A.J. van Dillen, J.H. Bitter, K.P. de Jong, J. Am. Chem. Soc., in press.

[36] M. Dixit, G.N. Subbanna, P.V. Kamath, J. Mater. Chem. 6 (1996) 1429.

[37] J. Ismail, M.F. Ahmed, P.V. Kamath, G.N. Subbanna, S. Uma, J. Gopalakrishnan, J. Solid State Chem. 114 (1995) 550.

[38] H.H. Willard, N.K. Tang, J. Am. Chem. Soc. 59 (1937) 1190.

[39] P. Porta, R. Dragone, G. Fierro, M. Inversi, M. Lo Jacono, G. Moretti, J. Chem. Soc., Faraday Trans. 88 (1992) 311.

[40] M.G. Mostafa, A. Matsumoto, K. Wase, Y. Kishi, Hydrometallurgy 57 (2000) 97.

[41] A.A. Khassin, T.M. Yurieva, G.N. Kustova, L.M. Plyasova, T.A. Krieger, I.S. Itenberg, M.P. Demeshkina, T.V. Larina, V.F. Anufrienko, V.N. Parmon, Mater. Res. Innovations 4 (2001) 251.

[42] K. Petrov, E. Deleva, O. Garcia-Martinez, Solid State Ion. 92 (1996) 303.

[43] D. Mealor, A. Townshend, Talanta 13 (1966) 1069.

[44] J.W. Geus, A.J. Van Dillen, Prep. Solid Catal. (1999) 460. 